\title{
AUTHOR INDEX Volume 62
}

Abdurohman \& Resosudarmo, Budy P., The Behavior of Fiscal Policy in Indonesia in Response to Economic Cycles

2 (2017) 377

Akinkunmi, Mustapha, see Ozsoz, Emre

1 (2017) 147

Ali, Amjad, see Shahbaz, Muhammad

4 (2017) 929

An, Lian, Ren, Xiaomei, Li, Huimin \& Xu, Jing, Exchange Rate and US Macroeconomy: Evidence from the Factor-Augmented Vector Autoregressive Model

$2(2017) 483$

Andersen, Thomas Barnebeck \& Malchow-Møller, Nikolaj, The

Macroeconomics of a Delayed Recovery from the Global Financial Crisis: A Comparative Approach

Ashraf, Ali, Hassan, M. Kabir \& Hippler Iii, William J., Monetary Shocks, Policy Tools and Financial Firm Stock Returns: Evidence from the 2008 US Quantitative Easing

Ay, Ismail Cagri, see Ozsoz, Emre

1 (2017) 27

1 (2017) 147

Aysan, Ahmet Faruk, Disli, Mustafa \& Ozturk, Huseyin, Financial Crisis, Macroprudential Policies and Depositor Discipline

1 (2017) 5

Baharudin, Azfar Hilmi \& Fei, Yap Su, A Contemporary Re-Examination of Malaysia's Economic Growth: The Issues of Equity, Efficiency and Liberalization

Bamidele, Ademola, see Ozsoz, Emre

Bandara, Yapa, see Yutian, Shi

Barbosa, Natália, Guimarães, Maria Helena \& Faria, Ana Paula, Single Market Non-Compliance: How Relevant is the Institutional Setting?

Basu, P. K., see Yutian, Shi

Behera, Smruti Ranjan, Saving-Investment Dynamics and Capital Mobility in the Newly Industrialized Countries

Bhattacharya, Mita, see Shahbaz, Muhammad

Cantekin, Kerem \& Elgin, Ceyhun, Extent and Growth Effects of Informality in Turkey: Evidence from a Firm-Level Survey

Carrasco-Gallego, José A., see Rubio, Margarita

Chia, Siow Yue, Modalities for ASEAN Economic Integration: Retrospect and Going Forward
2 (2017) 509

1 (2017) 147

5 (2017) 1097

5 (2017) 1115

5 (2017) 1097

2 (2017) 403

4 (2017) 929

5 (2017) 1017

1 (2017) 109

3 (2017) 561 
Chen, Lurong, Cuyvers, Ludo \& De Lombaerde, Philippe, ASEAN Economic Integration Compared: What Do the Numbers Tell Us? Chang, Tsangyao, see Li, Jing-Ping

3 (2017) 619

5 (2017) 1165

Chen, Qi-An \& Du, Fangzhou, Hedging of Credit Derivatives, Systematic Fluctuation and Banking Stability in China

4 (2017) 809

Cheng, Zhiming \& Smyth, Russell, China's Imbalanced Sex Ratio and Satisfaction with Marriage

4 (2017) 765

Cheo, Roland, Challenges Facing China in the "New Normal"? An Introductory Review

$4(2017) 761$

Cheo, Roland, Small Rewards or Some Encouragement? Using an Experiment in China to Test Extrinsic Motivation on Academic Performance

Ciżkowicz, Piotr \& Rzońcaz, Andrzej, Are Major Central Banks Blinded by the Analytical Elegance of Their Models? Possible Costs of Unconventional Monetary Policy Measures

Cottrel, Simon, see Dai, Pham Van

Cui, Yuling, Nahm, Daehoon \& Tani, Massimiliano, Employment Choice and Ownership Structure in Transitional China

Cuyvers, Ludo, see Chen, Lurong

Dai, Pham Van, Delpachitra, Sarath \& Cottrell, Simon, Real Exchange Rate and Economic Growth in East Asian Countries: The Role of Financial Integration

Das, Sanchita Basu, Sen, Rahul \& Srivastava, Sadhana, A Partial ASEAN Customs Union Post 2015?

De Lombaerde, Philippe, see Chen, Lurong

Delpachitra, Sarath, see Dai, Pham Van

Disli, Mustafa, see Aysan, Ahmet Faruk

Dou, Liyu, see Sng, Hui-Ying

$\mathrm{Du}$, Fangzhou, see Chen, Qi-An

Dua, Pami \& Tuteja, Divya, Impact of Eurozone Sovereign Debt Crisis on China and India

Elgin, Ceyhun, see Cantekin, Kerem

Esiyok, Bulent \& Ugur, Mehmet, A Spatial Regression Approach to FDI in Vietnam: Province-Level Evidence

Fang, Chen, see Ko, Sheng-Huei

Faria, Ana Paula, see Barbosa, Natália

Farvaque, Etienne \& Matsueda, Norimichi, Optimal Term Length for An Overconfident Central Banker

Fei, Yap Su, see Baharudin, Azfar Hilmi

Fu, Haiyan, see Shi, Junwei

Furuoka, Fumitaka, Unemployment Dynamics in the Asia-Pacific Region: A Preliminary Investigation
4 (2017) 797

1 (2017) 87

1 (2017) 163

2 (2017) 325

3 (2017) 619

1 (2017) 163

3 (2017) 593

3 (2017) 619

1 (2017) 163

1 (2017) 5

3 (2017) 703

4 (2017) 809

5 (2017) 1137

5 (2017) 1017

2 (2017) 459

2 (2017) 447

5 (2017) 1115

1 (2017) 179

2 (2017) 509

4 (2017) 905

5 (2017) 983 
Gan, Li, see Li, Feng

4 (2017) 783

Gibson, John, see Tan, Peck-Leong

5 (2017) 959

Goyal, Ashima, Intervention and Signaling: Interaction Between

Central Banks and FX Markets in an Emerging Market

$1(2017) 193$

Gudmundsson, Már, Global Financial Integration and Central Bank

Policies in Small, Open Economies

1 (2017) 135

Guimarães, Maria Helena, see Barbosa, Natália

5 (2017) 1115

Guo, Feng, see Zhang, Bo

4 (2017) 875

Guo, Lin, Income Inequality, Household Consumption and $\mathrm{CO}_{2}$

Emissions in China

2 (2017) 531

Hassan, M. Kabir, see Ashraf, Ali

1 (2017) 27

Heshmati, Almas \& Su, Biwei, Analysis of Gender Wage Differential in China's Urban Labor Market

2 (2017) 423

Hicks, John, see Yutian, Shi

5 (2017) 1097

Hippler Iii, William J., see Ashraf, Ali

1 (2017) 27

4 (2017) 875

Hur, Jung \& Lee, Hyun-Hoon, APEC has Indeed Created Intra-

Regional Trade: A Systematic Empirical Analysis

5 (2017) 1077

Jeong, Soo-Bin, Kim, Bong-Hwan, Kim, Tae-Hwan \& Moon, Hyung-

Ho, Unit Root Tests in the Presence of Multiple Breaks in Variance Jiang, Mingming, see Zhang, Bo

Jianzhong, Dai, Capital Requirement and Loan Suppliers of the

Regional Banks in China

2 (2017) 345

4 (2017) 875

4 (2017) 837

Kawai, Masahiro \& Naknoi, Kanda, ASEAN's Trade and Foreign

Direct Investment: Long-Term Challenges for Economic Integration

3 (2017) 643

Khan, Saleheen, see Shahbaz, Muhammad

4 (2017) 929

2 (2017) 345

Kim, Bong-Hwan, see Jeong, Soo-Bin

2 (2017) 345

Ko, Sheng-Huei, Kuo, Kuo-Hsing, Lee, Cheng-Te \& Fang, Chen,

Environmental Tax and Return Urban-Rural Migration

2 (2017) 447

Kochhan, Robert, see Li, Yanfei

5 (2017) 1195

2 (2017) 447

Kuo, Kuo-Hsing, see Ko, Sheng-Huei

5 (2017) 1223

Lal, Anil K., Foreign Direct Investment, Trade Openness and GDP in

China, India and Mexico

5 (2017) 1059

Lee, Cheng-Te, see Ko, Sheng-Huei

2 (2017) 447

Lee, Hyun-Hoon, see Hur, Jung

5 (2017) 1077

Li, Feng \& Gan, Li, The Effects of Replacing China's Two-Exam

College Entrance System with a One-Exam System

4 (2017) 783

Li, Huimin, see An, Lian

2 (2017) 483 
Li, Jing-Ping, Ranjbar, Omid \& Chang, Tsangyao, Unemployment Hysteresis in PIIGS Countries: A New Test With Both Sharp and Smooth Breaks

Li, Yanfei \& Kochhan, Robert, Policies and Business Models for the Electric Mobility Revolution: The Case Study on Singapore Liu, Zhixin, see $\mathrm{Xu}$, Yingying

Mah, Jai S., Globalization and Economic Growth in Cambodia

5 (2017) 1195

4 (2017) 859

2 (2017) 363

Majeed, Muhammad Tariq, Inequality, FDI and Economic

Development: Evidence from Developing Countries

Malchow-Møller, Nikolaj, see Andersen, Thomas Barnebeck

Matsueda, Norimichi, see Farvaque, Etienne

Matthews, Kent, see Yin, Wei

Melendez, Anna Cassandra, see Menon, Jayant

Menon, Jayant \& Melendez, Anna Cassandra, Realizing an ASEAN

Economic Community: Progress and Remaining Challenge

Moon, Hyung-Ho, see Jeong, Soo-Bin

Murphy, Tom, see Yutian, Shi

Nagarajan, Renuga, Teixeira, Aurora A. C. \& Silva, Sandra, The

Impact of Population Ageing on Economic Growth: A Bibliometric Survey

Nahm, Daehoon, see Cui, Yuling

Naknoi, Kanda, see Kawai, Masahiro

Ozsoz, Emre, Akinkunmi, Mustapha, Ay, Ismail Cagri \& Bamidele, Ademola, How CBN Confronted the Meltdown: The Global

Financial Crisis and the Central Bank of Nigeria's Response

Ozturk, Huseyin, see Aysan, Ahmet Faruk

Pitakdumrongkit, Kaewkamol, Beyond the Secretariat: Addressing

Governance Issues in ASEAN Economic Community

Rana, Pradumna Bickram, Special Issue of the Singapore Economic

Review - ASEAN's Long Term Economic Potential and Vision

Rana, Pradumna Bickram, see Sng, Hui-Ying

Ranjbar, Omid, see Li, Jing-Ping

Ren, Xiaomei, see An, Lian

Resosudarmo, Budy P., see Abdurohman

Riet, Ad van, A New Era for Monetary Policy: Challenges for the

European Central Bank

Rubio, Margarita \& Carrasco-Gallego, José A., Spain and the Crisis:

Housing Prices, Credit and Macroprudential Policies

Rzońcaz, Andrzej, see Ciżkowicz, Piotr

Sen, Rahul, see Das, Sanchita Basu

5 (2017) 1039

5 (2017) 1179

1 (2017) 179

1 (2017) 227

3 (2017) 681

3 (2017) 681

2 (2017) 345

5 (2017) 1097

2 (2017) 275

2 (2017) 325

3 (2017) 643

1 (2017) 147

1 (2017) 5

3 (2017) 741

3 (2017) 555

3 (2017) 703

5 (2017) 1165

2 (2017) 483

2 (2017) 377

1 (2017) 57

1 (2017) 109

1 (2017) 87

3 (2017) 593

Shahbaz, Muhammad, Khan, Saleheen, Ali, Amjad \& Bhattacharya, Mita, The Impact of Globalization on $\mathrm{CO}_{2}$ Emissions in China 
Sharma, Kishor, see Yutian, Shi

5 (2017) 1097

Shi, Junwei \& Fu, Haiyan, Has the Industrial Structure of Western

Provinces in China Been Differential? Evidence from the SIP

Framework

4 (2017) 905

Silva, Sandra, see Nagarajan, Renuga

2 (2017) 275

Smyth, Russell, see Cheng, Zhiming

4 (2017) 765

Sng, Hui-Ying, Dou, Liyu \& Rana, Pradumna Bickram, Catalyst of

Business Cycle Synchronization in East Asia

3 (2017) 703

Song, Jeongseok, Yang, Daecheon \& Kwon, Soonwon, FDI

Consequences of Downward Wage-Cost Rigidities

Srivastava, Sadhana, see Das, Sanchita Basu

5 (2017) 1223

3 (2017) 593

Stavins, Robert N., The Evolution of Environmental Economics: A

View from the Inside

2 (2017) 251

2 (2017) 423

Tan, Peck-Leong \& Gibson, John, Does Outsourcing Household

Production Harm Future Human Capital? Evidence from Malaysia

5 (2017) 959

Tan, See Seng, Rethinking "ASEAN Centrality” in the Regional

Governance of East Asia

3 (2017) 721

2 (2017) 325

2 (2017) 275

Teixeira, Aurora A. C., see Nagarajan, Renuga

Tsai, Chun-Li, The Heterogeneous Impact of Children on the

Participation of Married Women in the Labor Market in Taiwan

Tuteja, Divya, see Dua, Pami

2 (2017) 297

5 (2017) 1137

Ugur, Mehmet, see Esiyok, Bulent

2 (2017) 459

2 (2017) 483

Xu, Yingying, Liu, Zhixin \& Zhang, Xing, Heterogeneous or

Homogeneous Inflation Expectation Formation Models: A Case

Study of Chinese Households and Financial Participants

4 (2017) 859

5 (2017) 1223

Yang, Daecheon, see Song, Jeongseok
Yin, Wei \& Matthews, Kent, Single Versus Multiple Banking

Relationships-Evidence from Chinese Lending Market

1 (2017) 227

Yutian, Shi, Hicks, John, Basu, P. K., Sharma, Kishor, Bandara, Yapa

\& Murphy, Tom, Balancing Act: Adjustment of China's Economy to

Secure Sustainable Growth

5 (2017) 1097

Zhang, Bo, Hu, Jinyan, Jiang, Mingming \& Guo, Feng, Monetary

Shocks and Stock Market Fluctuations: With an Application to the

Chinese Stock Market

4 (2017) 875

Zhang, Xing, see Xu, Yingying

4 (2017) 859 